\title{
Physiopathology and etiology of stone formation in the kidney and the urinary tract
}

\author{
Andrew P. Evan
}

Received: 20 October 2008 /Revised: 22 December 2008 /Accepted: 29 December 2008 / Published online: 7 February 2009

(C) IPNA 2009

\begin{abstract}
All stones share similar presenting symptoms, and urine supersaturation with respect to the mineral phase of the stone is essential for stone formation. However, recent studies using papillary biopsies of stone formers have provided a view of the histology of renal crystal deposition which suggests that the early sequence of events leading to stone formation differs greatly, depending on the type of stone and on the urine chemistry leading to supersaturation. Three general pathways for kidney stone formation are seen: (1) stones fixed to the surface of a renal papilla at sites of interstitial apatite plaque (termed Randall's plaque), as seen in idiopathic calcium oxalate stone formers; (2) stones attached to plugs protruding from the openings of ducts of Bellini, as seen in hyperoxaluria and distal tubular acidosis; and (3) stones forming in free solution in the renal collection system, as in cystinuria. The presence of hydroxyapatite crystals in either the interstitial or tubule compartment (and sometimes both) of the renal medulla in stone formers is the rule and has implications for the initial steps of stone formation and the potential for renal injury.
\end{abstract}

Keywords Randall's plaque $\cdot$ Nephrolithiasis $\cdot$ Calcium oxalate $\cdot$ Calcium phosphate

\footnotetext{
A. P. Evan $(\bowtie)$

Department of Anatomy and Cell Biology, Indiana University School of Medicine,

635 Barnhill Drive, MS 5055,

Indianapolis, IN 46220, USA

e-mail: evan@anatomy.iupui.edu
}

\section{Prevalence of stone disease}

Approximately $5 \%$ of American women and $12 \%$ of men will have a kidney stone at some time in life, at an annual cost of $\$ 2.1$ billion [1]. The prevalence of kidney stones in the United States of America rose by 37\% between 1976-1980 and 1988-1994 in both genders [2]. The risk of stone disease is significantly lower among non-Hispanic African Americans and Mexican Americans than among non-Hispanic Caucasians for both genders [2]. Another worrisome statistic is the documented increase in the prevalence of calcium phosphate $(\mathrm{CaP})$ in stones over the past two decades, with most $\mathrm{CaP}$ stone formers being female [3, 4]. A strong association was identified between the numbers of sessions of extracorporeal shock wave lithotripsy (SWL) the patient received with conversion of calcium oxalate $(\mathrm{CaOx})$ stones to increasing levels of $\mathrm{CaP}$ in recurring stones [5]. The presence of $\mathrm{CaP}$ stones raises clinical concern, specially those stones containing brushite (calcium monohydrogen phosphate dihydrate, $\mathrm{CaHPO}_{4}$ ), because of their increased hardness and, thus, greater difficulty to be comminuted by shock wave lithotripsy [6].

Studies on the geographic variation in the prevalence of kidney stone disease have shown a 50\% higher prevalence in the southeast (the 'kidney stone belt') than the northwest [7], possibly associated with a changing state of dehydration related to high summertime temperatures and resulting in a low urine volume. Given the temperature rise worldwide due to the effects of global warming, it has been predicted that there could be an increase of 1.6-2.2 million lifetime cases of kidney stone by 2050, particularly in the southeast regions of the USA [8]. 


\section{Kidney stone types and role of supersaturation}

Stones along the urinary tract can be located in the kidneys, ureters and urinary bladder (Fig. 1). Kidney stones are categorized as either staghorn (filling numerous major and minor calices) or non-staghorn. Non-staghorn stones are described as calyceal or pelvic in location, while ureteral stones are defined as proximal, middle or distal. Kidney stones less than $5 \mathrm{~mm}$ in diameter have a high chance of being passed, while those of 5-7 $\mathrm{mm}$ have a $50 \%$ chance, and those over $7 \mathrm{~mm}$ almost always require urological intervention. Renal colic (flank pain) develops as the stone begins its passage down the urinary tract. While approximately $90 \%$ of stones are successfully passed out of the urinary tract, the remaining stones generally have to be surgically removed by ureteroscopy or percutaneous nephrolithotomy or comminuted by the non-invasive technique, shock wave lithotripsy [9].

A majority of kidney stones are calcium stones, with calcium oxalate $(\mathrm{CaOx})$ and calcium phosphate $(\mathrm{CaP})$ accounting for approximately $80 \%$ of all of these stones, uric acid (UA) about 9\%, and struvite (magnesium ammonium phosphate hexahydrate, from infection by bacteria that possess the enzyme urease) approximately $10 \%$, leaving only $1 \%$ for all the rest (cystine, drug stones, ammonium acid urate). Kidney stones are named for their solid phase, and stone type is a faithful representation of the

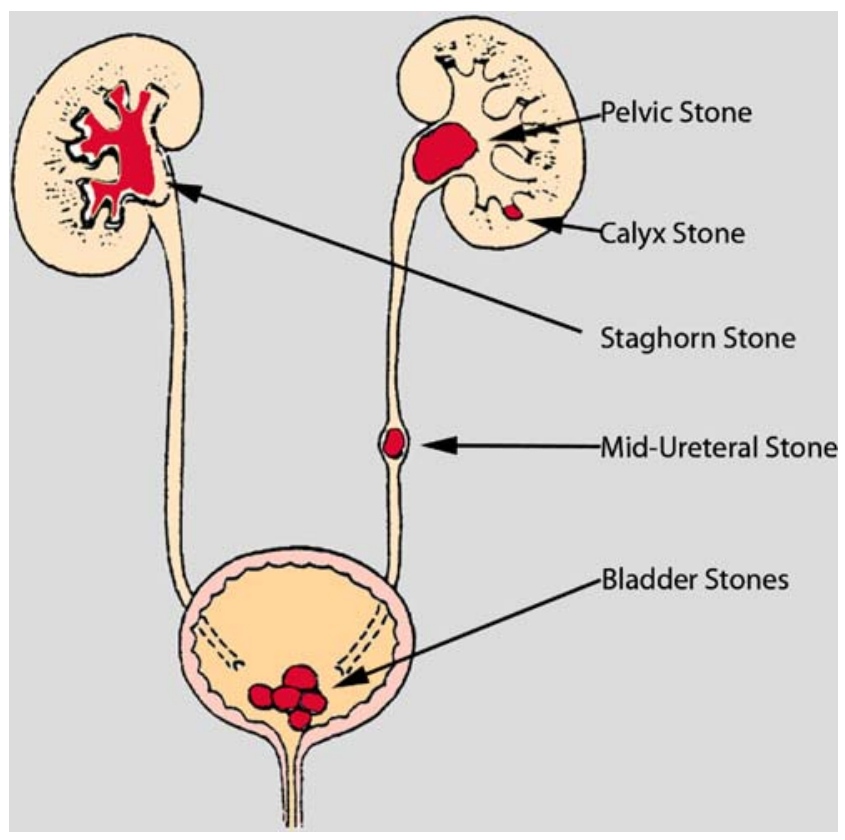

Fig. 1 Location of staghorn and non-staghorn kidney stones. Staghorn stones fill various amounts of the renal collection system. Nonstaghorn stones can be very variable in size and can be found in a major or minor calyx, in the renal pelvis or at different sites along the ureters (proximal, middle or distal). Stones can also be found in the urinary bladder supersaturation present in the urine when the stone was formed. Modern medical treatments for stone prevention are largely based on methods to decrease supersaturation effectively, and, thus, we are most interested in the pathophysiology leading to specific types of supersaturation. However, treatments may pose their own problems. Potassium citrate is effective, but, along with SWL, they may promote the formation of CaP stones [5], as mentioned above. Because potassium citrate increases (alkalinizes) urine $\mathrm{pH}$, this new $\mathrm{pH}$ condition would favor the retention of apatite, in that apatite becomes increasingly more insoluble at higher $\mathrm{pH}$ levels.

However, many pathways can lead to increased urinary supersaturation [10]. As one example, increased calcium oxalate supersaturation may result from low urine volume or excessive excretion of calcium or oxalate, or combinations of these factors. Hypercalciuria and hyperoxaluria can each result from interaction of genetic susceptibility and environmental triggers, in varying proportions. A state of hyperoxaluria may result from rare autosomal recessive genetic disorders of oxalate synthesis (primary hyperoxaluria types 1 and 2), increased intestinal oxalate absorption secondary to malabsorptive disease (enteric hyperoxaluria), dietary habits (high oxalate intake coupled with low calcium intake), alteration in gut flora which may decrease oxalate degradation in the colon, and, potentially, abnormalities of anion transporters found in both gut and kidney. Despite all this knowledge about urinary supersaturation, the most important data appear to be related to the links between genetic variability and urine calcium excretion and $\mathrm{pH}$, for these risk factors seem to be at the very center of the problem of kidney stone disease [10].

\section{Hypotheses of stone formation and growth}

Fixed and free particle theories Kidney stone development is thought to require the formation of crystals in the tubular fluid, followed by crystal retention and accumulation in the kidney [11]. Three pathways of stone formation and growth are currently being investigated (Fig. 2). The first hypothesis, termed the free particle model, states that crystal nuclei form by homogeneous nucleation in the lumen of the nephron under conditions of a phase change (increasing supersaturation) in the dissolved salts present in the ultrafiltrate [12]. Subsequently, these nuclei would grow in size and eventually lodge (be retained) in the lumen of the distal nephron, causing obstruction of that tubular segment. Obviously, free particle formation could occur in the renal collection system at the level of the minor calyx. The second hypothesis, termed the fixed particle model, also requires crystal nuclei to form in the lumen of the nephron, and then adhere to the apical surface of the tubular 


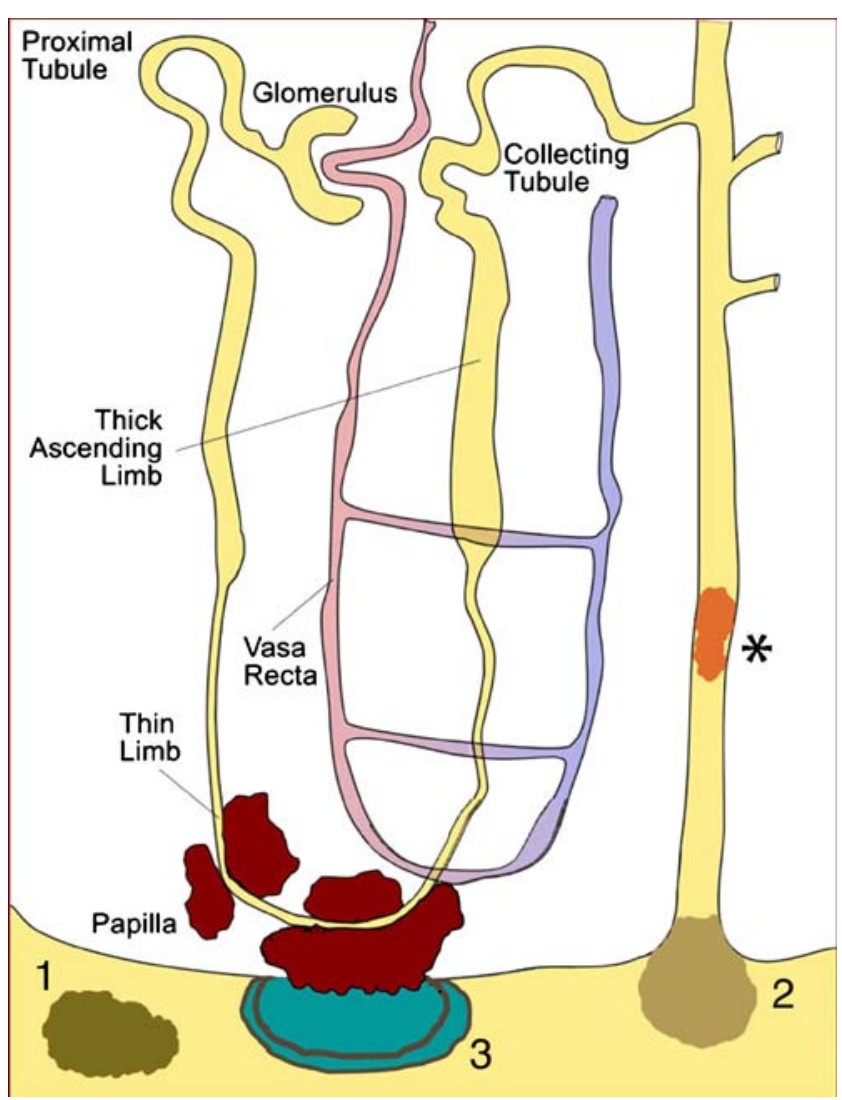

Fig. 2 Illustration of three pathways for kidney stone formation and growth. The first pathway (1) represents 'free particle' formation, either in the collection system of the kidney or along the nephron (asterisk). The second pathway (2) requires crystal nuclei to form in the lumen of a nephron at sites of cell injury, which results in crystal attachment and growth. In this illustration, crystal attachment occurred at the opening of a duct of Bellini, and a plug of crystalline material projects into a minor calyx. The third pathway (3) suggests that crystals in the urine can become attached to a site of exposed crystalline deposits of interstitial calcium phosphate following loss of the normal urothelial covering of the renal papilla

epithelium [13, 14]. While a number of mechanisms have been proposed to model this crystal-cell attachment step, the most commonly cited model requires renal cell injury, probably as a result of high tubular oxalate levels [15]. Once the crystal-cell attachment step has occurred, the crystal nuclei would be fixed in position and exposed to the potentially supersaturated ultrafiltrate that would facilitate further growth of these crystals. Both these theories could result in the plugging of the nephron and lead to intratubular calcification, termed tubular nephrocalcinosis [11]. Randall, in his historic paper in 1940, described intraluminal calcification (papillary lesion type II) or nephrocalcinosis in only 23 cases and compared it to the more common finding (204 cases) of interstitial plaque (papillary lesion type I), placing the type II lesion in a category different from that of type I [16]. We have shown that, in patients who form brushite stones [17], or who form apatite [hydroxyapatite, $\left.\mathrm{Ca}_{5}\left(\mathrm{PO}_{4}\right)_{3}(\mathrm{OH})\right]$ stones because of distal renal tubular acidosis (dRTA) [18], or patients with calcium oxalate stone due to obesity bypass procedures [19], or patients with cystinuria [20], their inner medullary collecting ducts (IMCDs) are plugged (tubular nephrocalcinosis) with cystine, which leads to total destruction of the lining cells and focal sites of interstitial fibrosis. However, it is unclear how the free or fixed particle hypotheses could lead to clinical stone formation (i.e. a stone in the renal pelvis large enough to obstruct the ureter), except that either the free or fixed particle process, or both, are occurring in the lumen of the ducts of Bellini and/or in the renal pelvis.

Randall's plaque hypothesis A third pathway suggests that crystals in the urine can become attached to a site of exposed crystalline deposits of interstitial calcium phosphate (termed Randall's plaque), following the loss of the normal urothelial covering of a renal papilla (Fig. 2). An anchored nidus of urinary crystals could form as an overgrowth on the interstitial plaque, permitting a fixed stone to form and potentially grow over many years. This theory is explicit in stating that sites of interstitial plaque are the initiating lesions. Randall examined 1,154 pairs of cadaveric kidneys by carefully opening the renal pelvis of each kidney and examining each accessible papilla with a hand lens [16]. This examination revealed an "innocent" appearing lesion that was a cream-colored area near the papillary tip and appeared to be subsurface or subepithelial in location. This lesion was seen in $20.5 \%$ of all the kidneys he studied. By light microscopy, the lesion was found to be a plaque of calcium salts deposited in the interstitial tissue and definitely not intraluminal in location. Evidence of inflammation was rarely found, and deposits were localized initially to interstitial collagen material as well as tubular basement membranes. Subsequently, the deposits appeared to fill much of the intertubular space. Chemical analysis of the regions of plaque showed calcium, nitrogen, carbon dioxide and phosphorus. His next major observation was the finding of a small stone $(2 \mathrm{~mm})$ that projected into the lumen of the renal pelvis. It was firmly attached to an area of visible calcium plaque and found to be composed of calcium phosphate. Such stones were found attached to papillae in 65 kidneys. Randall was able to study several stones still attached to the papillary wall and concluded from these studies that (1) attached stones were growing from and were supported by interstitial calcium plaque; (2) the sites of interstitial plaque could lose their urothelial cell covering, allowing the plaque to be exposed to the calyceal urine, and (3) some detached stones had a concave surface with patches of phosphate material (possibly representing the attachment site to the interstitial plaque). The observations Randall made from 1,154 pairs of post-mortem kidneys were earth shattering in their importance and 
originality. However, what Randall was not able to determine because of the techniques available to him in the 1930s was the composition of the mineral in the plaque, the type of crystalline material that formed right at the site of overgrowth, and the transition of mineral type (i.e. calcium oxalate, uric acid, calcium phosphate) from the site of attachment into the body of the stone. In addition, Randall lacked extensive clinical data on each of the kidneys he examined and, therefore, suggested that all stones formed according to his hypothesis. Consequently, his idea was easily challenged.

\section{Randall's plaque unique to idiopathic calcium oxalate stone formers}

Endoscopic and histologic observations Our group set out to test the hypothesis that regions of Randall's plaque develop in unique anatomical sites of the kidney and that their formation is conditioned by specific stone-forming pathophysiologies. To test this hypothesis, we employed state-of-the-art digital endoscopic equipment during percutaneous nephrolithotomy (PNL) for stone removal. We chose to study idiopathic calcium oxalate stone formers (ICSFs) as our primary group of stone formers because they represent approximately $75 \%$ of all stone formers. This protocol allowed us to obtain digital images of all papillae for plaque surface determinations and permitted us to obtain papillary biopsies of regions with and without plaque. During intraoperative endoscopy, we identified irregularly shaped regions of whitish material generally located on the papillary tip and usually surrounding the openings of the ducts of Bellini (Fig. 3a), the same plaque material described by Randall. The plaque is located deep in the urothelium (suburothelial) and has a smooth outer surface, except where it is pitted due to the removal of an attached stone. Light microscopic examination of Yasuestained papillary biopsies revealed minute deposits of mineral, first laid down in the basement membrane beneath cells of a specific portion of the urinary tubule, the thin limbs of Henle, as they pass near the tip of renal papillaclose to where urine drips into the minor calyx (Fig. 3b). Initially, these mineral deposits are seen as electron-dense spherical objects of approximately $50 \mathrm{~nm}$ in diameter to multilayered spheres with alternating light (mineral layer) and dark (matrix layer) rings or bands (Fig. 3d, insert). The individual deposits appear then to coalesce on the collagen bundles in the interstitial space and become embedded in an electron-dense matrix material, generating islands of plaque. These islands extend down to the basal side of the urothelium and encase the ducts of Bellini (Fig. 3c). In order to determine the mineral composition of the intersti- tial plaque, we developed a protocol to analyze these small sites of crystalline material using Fourier transform infrared microspectroscopy ( $\mu$-FTIR). The mineral in the individual plaque spherules was always determined to be biological apatite (calcium phosphate). In addition, we have identified osteopontin as one of the proteins forming the crystalmatrix interface [21] of these spherules (Fig. 3e), while heavy chain 3 (H3) of the inter-alpha-trypsin molecule [22] was located in the matrix layer (Fig. 3f). No evidence of cell injury, inflammation, interstitial fibrosis or intratubular crystalline material was detected in any of the ICSFs' papillary biopsies [23].

Stones in ICSFs are attached to plaque Randall was convinced that interstitial plaque was a perquisite for stone formation and growth [16]. Unfortunately, he was not able to obtain a detailed clinical history on each of the autopsy kidneys he had studied, so his theory that stones grow attached to sites of interstitial plaque was stated in very general terms. Generality is crucial to our understanding of stone pathogenesis, because if stones indeed grow on plaque as a rule, then how they do so, and how plaque itself forms and enlarges, become primary clinical research objectives. The problem is especially complicated because, in other groups of calcium oxalate stone formers, apart from ICSFs, growth of stone on plaque is not a prominent mechanism. Therefore, we conducted a series of studies at the time of PNL where every attached stone in a group of ICSFs could be accounted for as attached to plaque or not. Figure 4 shows such a stone fixed to a papilla at a site of plaque. Matlaga and colleagues performed a retrospective study of ICSF patients at the time of their PNL procedures for stone removal and found that 11 of 23 patients had attached stones, with $91 \%$ of these stones at sites of plaque [24]. Miller and colleagues [25] have recently repeated this study, using a prospective design. They studied nine ICSF patients who had a total of 115 stones, of which 81 were attached to a site of Randall's plaque. Based on the observed data, the final point estimate for the number of stones attached to plaque was 0.754 (95\% confidence interval $0.575,0.933), P=0.013$, which suggests that, in ICSF patients, stones develop attached to plaque.

Ultrastructural features of stone-plaque junction As stated earlier in this paper, those attached stones that have been plucked from papillae, generally have been found to have an irregular concave surface that fits against a papilla and a smooth convex surface that faces the urinary space [16]. Often, the concave surface has been found to have a stock or umbilicus, thought to be made up of plaque and in continuity with the interstitial plaque before the stone had been detached from the papilla. Cifuentes-Delatte et al. [26] and Pieras et al. [27] have also observed a "footprint" of a 
Fig. 3 Endoscopic and histologic images of Randall's plaque seen in an idiopathic calcium oxalate stone former. a A papilla with two attached stones (arrows) and several sites of Randall's plaque (arrowheads). b Light microscopy shows the initial sites of crystal deposits (arrows) in the basement membrane of the thin loops of Henle. These individual deposits collect in the interstitial space (c) all the way to the urothelium (arrow), embedded in a dense coating of matrix. The individual deposits (arrow, d) are multilaminated spheres of alternating layers of crystal (electron lucent) and matrix (electron dense).

These spheres have both osteopontin (e) and the heavy chain of the inter-alpha-trypsin molecule (arrow, f)
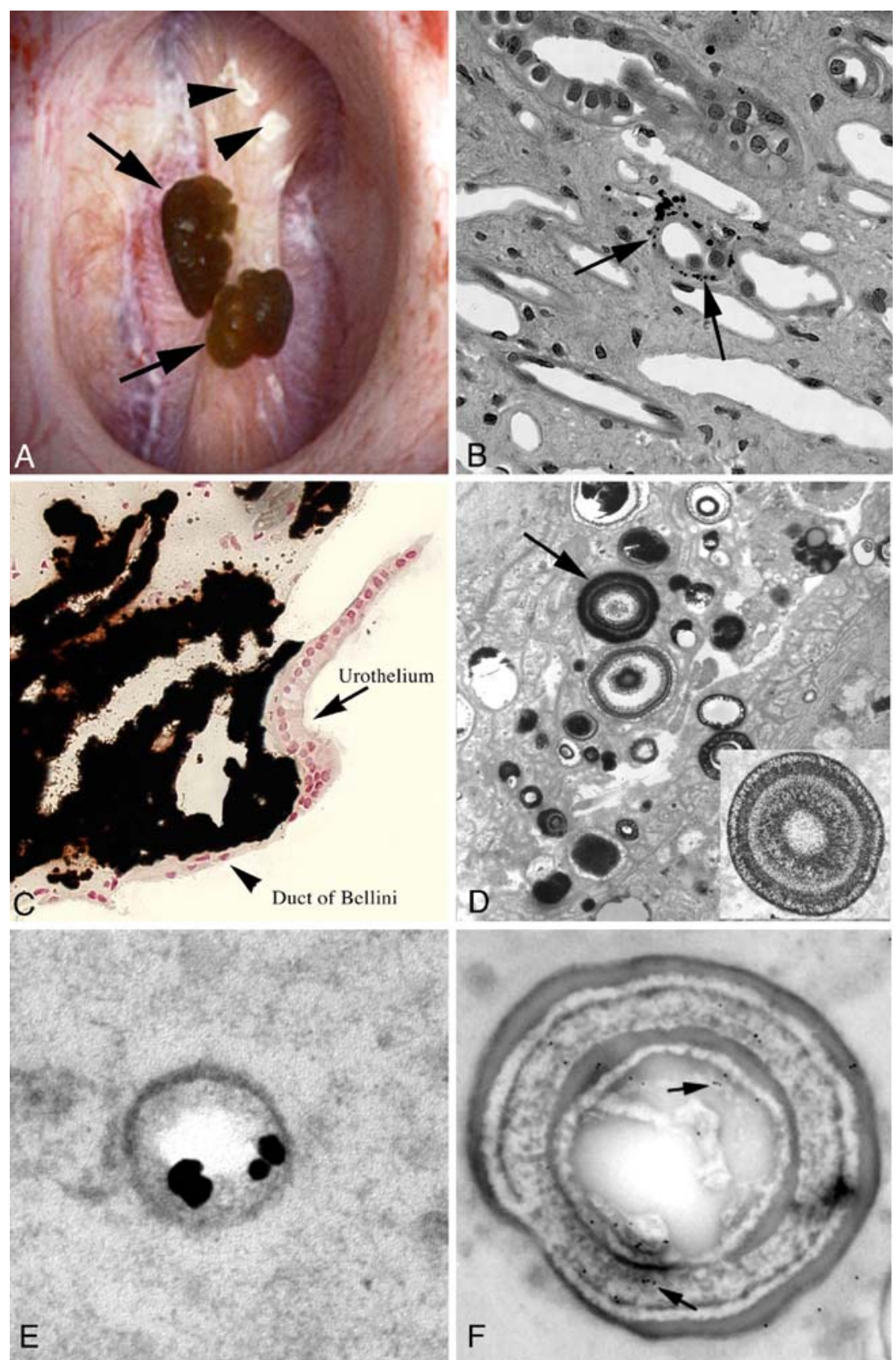

papilla as a depressed zone ("umbilication") on the concave surface of the stone, which corresponded to the shape of the tip of a papilla, and this concave surface contained mineral detached from interstitial plaque. Daudon and colleagues recently reported on an analysis of 5,401 stones with umbilications [28]. They found the main mineral component of this plaque material to be carbapatite (91\%), with lesser amounts of amorphous carbonated calcium phosphate, sodium hydrogen urate or uric acid. These observations again support the ideas laid out by Randall [16]. Thus, calcium oxalate stones in ICSF patients appear to grow like stalactites adherent to the tips of kidney papillae and, typically, are made of layers of calcium oxalate surrounding a core of apatite.

All these findings lead us to the next critical question: what is the mineral that forms the overgrowth on the interstitial plaque? By answering this issue, we will have insight into the initiating event for stone growth on interstitial plaque, which can then be possibly used to determine ways to block this process from occurring. Randall desperately attempted to address this question but failed. We presently have the techniques necessary to carry out this analysis, and we obtained an en bloc biopsy of a very small stone [29] which 


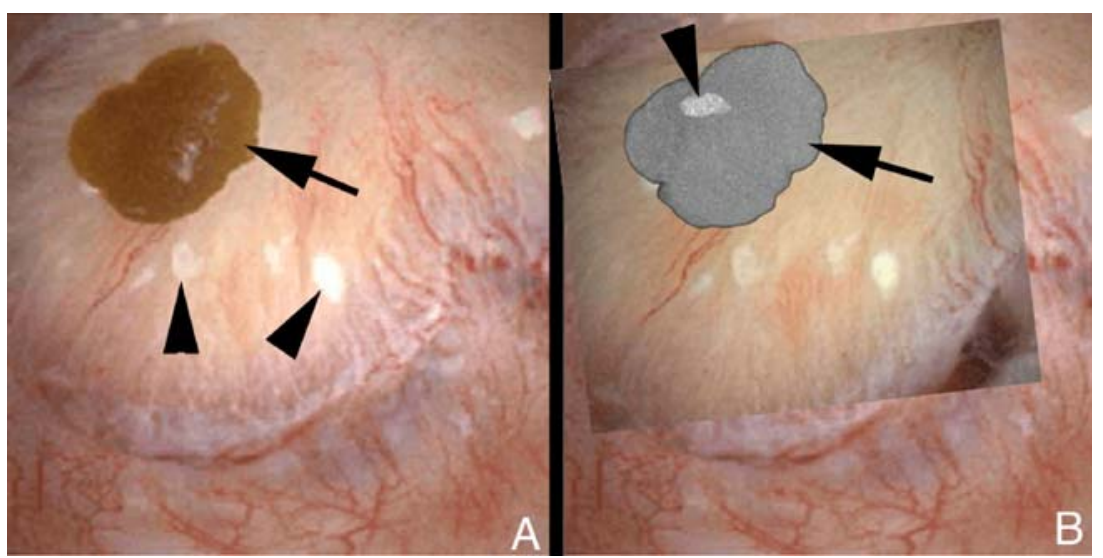

Fig. 4 Correspondence between tissue plaque and attachment site on the same stone. a Endoscopic image of $\mathrm{CaOx}$ stone (arrow) on a papilla from an idiopathic calcium oxalate stone former. Multiple sites of Randall's plaque (arrowheads) are easily seen. Following removal of the attached stone, it was imaged by micro-computed tomography so that the attachment site of calcium phosphate could be localized and matched to the site of Randall's plaque in the papilla tissue. b The stone (arrow) was ghosted so that the site of calcium phosphate could be readily seen (arrowhead) and placed over the tissue site of calcium phosphate so that it could be documented that each stone had been attached and attached to a site of Randall's plaque has permitted us the chance to study the anatomy and microstructure of the plaque-stone interface (Fig. 5a, b). After demineralization and sectioning, one can see plaque on the stone surface at the old attachment site and the matching region of exposed plaque on the renal tissue surface (Fig. 5c). Ultrastructural analysis at the old attachment site (Fig. 5d) reveals loss of urothelial cells; above the tissue, in the old urinary space, rafts of crystals (arrows) are imbedded in a homogeneous gray matrix accompanied by cell debris (arrowheads). Higher resolution of the region within the square (Fig. 5d) reveals that the exposed plaque is covered by a dark ribbon-like layer of alternating lamina of crystal-white in this figure-and black organic material (arrow). Crystals extend from the rafts into the outer surface of the ribbon (arrowheads). Higher resolution of the square (Fig. 5d, insert) shows masses of tiny crystals growing directly in the outer ribbon (asterisk), the attachment site of one of the large raft crystals (arrows), and the crystals within the inner ribbon layers - in white. The blow-up insert shows the microcrystals within the inner lamina of the ribbon; one can count four white and five organic layers in this specimen. At the same resolution, but at another location, one again sees the large raft crystals imbedded in their homogeneous matrix (double arrows) and masses of crystals growing in the outer layer of the ribbon (arrow).

On the stone itself, one finds large rectangular crystals (arrows) at the tissue-stone interface, similar to those in the raft (not shown). Moving upward, and into the bulk of the actual stone and away from the tissue-stone interface, one can see that these big crystals give way to masses of small crystals typical of stone architecture. All the large and small crystals are imbedded in matrix. FTIR analysis of tissue sites of Randall's plaque, the tissue-stone interface and the overgrowth zone shows a transition from biological apatite in the interstitial plaque to amorphous apatite in the overgrowth zone (Fig. 5e and f). Progressing outward from the overgrowth zone, the actual stone is developing, so there is a transition from apatite with some $\mathrm{CaOx}$ crystals to only $\mathrm{CaOx}$ crystals.

These observations suggest a plausible sequence of events (Fig. 6). First, there is the formation of interstitial plaque, of which most extends to the basal side of the urothelium. Next, the interstitial plaque is exposed to the urine because the urothelial cells are either damaged or have undergone cell death. Subsequently, the exposed interstitial plaque is overlaid with a new layer of matrix material that is derived from the urinary proteins and ions. Next, tiny amorphous apatite crystals form in this new matrix layer, in successive waves, forming a continuous ribbon-like structure of alternating layers of matrix and crystals that covers the entire region of exposed plaque. At some point in time the rate and quantity of crystal formation permits explosive outward growth of large and small matrix-coated crystals. This rapid formation of apatite crystals results in a heaping up of various sized crystals into the urinary space. Next, a combination of apatite and $\mathrm{CaOx}$ crystals layer the overgrowth site as a result of the supersaturation levels of these ions in the urine. This is the first evidence of a new attached $\mathrm{CaOx}$ stone forming. Subsequently, the mixture of apatite and $\mathrm{CaOx}$ crystals is primarily $\mathrm{CaOx}$. Thus, it is our understanding that the growth of $\mathrm{CaOx}$ stones in ICSF patients requires a site of Randall's plaque, and when this site of plaque is exposed to the proteins and ions in the urine of a stone former, a new stone develops, attached to the site of interstitial plaque. 


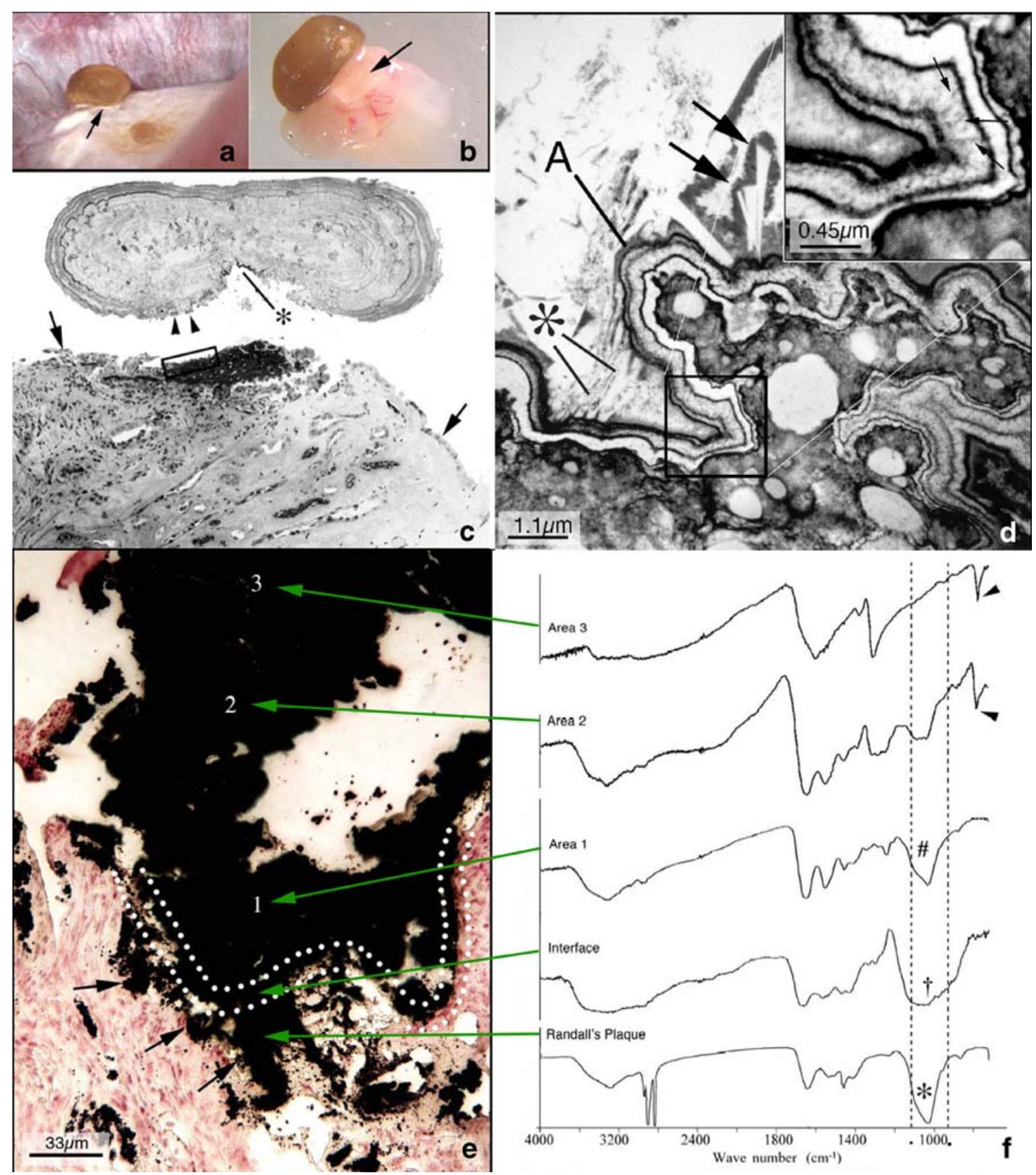

Fig. 5 Ultrastructural and $\mu$-FTIR features of the attachment site of a kidney stone from an idiopathic calcium oxalate stone former. a Endoscopic view of a $0.5 \mathrm{~mm}$ stone seen attached to a papilla tip at the site of a Randall's plaque (arrow). b The same stone, seen by light microscopy, with underlying tissue (arrow) after biopsy. c The same stone-tissue complex as in $\mathbf{b}$ but after demineralization. Note that the stone is separated from the underlying tissue (rectangular box). Some tissue is still stuck to the stone (asterisk). The arrowheads show a region of cellular debris. The arrows point to areas on the papilla that still have a urothelial covering; these cells are lost at the stone-tissue junction. d High magnification transmission electron micrograph of the tissue attachment site. The region of Randall's plaque (lower right) is seen covered by a multi-layered ribbon-like structure with crystalline and matrix material, which is highlighted (arrows) in the insert (upper right). The region $A$ shows small (asterisk) and large (arrows) crystals embedded in the outer (urine) side of the ribbon. By $\mu$-FTIR (e and f), the mineral in the Randall's plaque (arrows in e) is shown to be apatite (asterisk in f), amorphous apatite (dagger in $\mathbf{f}$ ) at the tissue-stone interface (outlined by dotted lines), back to apatite (number sign in $\mathbf{f}$ ) in the stone area closest to the interface and then progressing from a mixture of apatite to just $\mathrm{CaOx}$ (arrowheads in $\mathbf{f}$ ) 


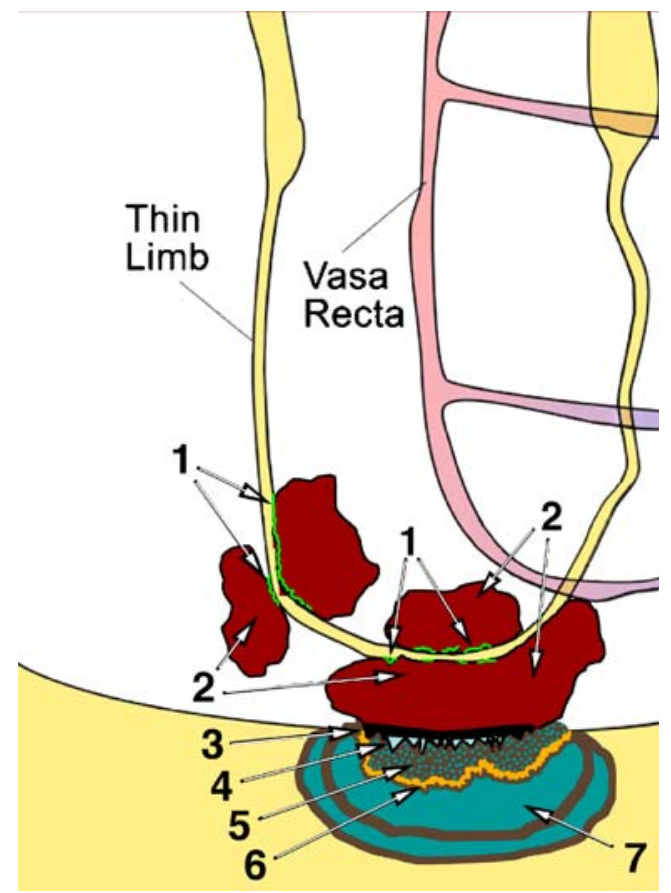

Fig. 6 Schematic representation of stone development in idiopathic calcium oxalate stone formers. The sequence of steps are as follows: 1 apatite deposits develop in the basement membrane of the thin loops of Henle; 2 these apatite deposits extend into the interstitial space and are embedded in matrix, forming islands of interstitial plaque termed Randall's plaque; 3 these areas of interstitial plaque are exposed to the urine due to a loss of urothelial covering; 4 urine proteins and ions coat the exposed interstitial plaque; 5 a layer of amorphous apatite forms on top of the interstitial plaque, and this new mineral layer is coated with urine matrix molecules; 6 a layer of biological apatite with matrix coating forms on the amorphous apatite; 7 a layer of both apatite and $\mathrm{CaOx}$ forms, and, at the outer margin of this small stone, only $\mathrm{CaOx}$ is found

\section{Stone forming attached to plugs or in free solution}

Our biopsy and mapping studies have now included not only ICSF patients but patients with brushite stones [17], those who form apatite stones because of distal renal tubular acidosis (dRTA) [18] or patients with calcium oxalate stones due to obesity bypass procedures [19, 23] or patients with cystinuria [20], or stone patients with primary hyperparathyroidism [30]. Table 1 summarizes the different histopathologic changes in these stone formers. While trace amounts of interstitial plaque can be found in all kidneys [31], large amounts of Randall's plaque are unique to ICSFs and correlate with urine volume, urine calcium level and urine $\mathrm{pH}$ [32] as well as the number of stones adjusted for duration of stone formation [33]. Other stone forming groups show varying degrees of plugging of their inner medullary collecting ducts (IMCDs), which leads to total destruction of the lining cells and focal sites of interstitial fibrosis and small amounts of plaque. Fixed stones can form from those plugs protruding from dilated ducts of Bellini. Brushite (Fig. 7), dRTA, and primary hyperparathyroid stone formers are the best example of this pathway. However, these stones have never been found to be $\mathrm{CaOx}$ stones but, rather, apatite stones. Risk factors for these stone formers include an alkaline urinary $\mathrm{pH}$ and the number of extracorporeal shock wave lithotripsy sessions [5]. The primary hyperparathyroid stone formers also have plaque to which attached $\mathrm{CaOx}$ stones are commonly found. Finally, there are patients that have undergone intestinal bypass surgery for obesity and cystinuric stone formers (Fig. 8) in whom the stones appear to have formed in free solution, in that their stones are free-floating (unattached). Generally, these patients have greatly elevated urinary oxalate levels after surgery. Thus, the single unattached $\mathrm{CaOx}$ stones found in these patients have probably formed directly in the renal collection system as a result of the elevated supersaturation levels of oxalate.

\section{Conclusion}

There appear to be three pathways for kidney stone formation: (1) overgrowth on sites of Randall's plaque, (2) growth on plugs from dilated ducts of Bellini, and (3) in free solution. The majority (approximately $75 \%$ ) of $\mathrm{CaOx}$ stones are formed attached to sites of Randall's plaque and represents all ICSF patients. In all other types of kidney stone formers that we have studied, plugs were formed along the inner medullary collecting ducts and ducts of Bellini, which can serve as attachment sites for developing stones. These stones found attached to plugs

Table 1 The different histopathologic changes seen in stone formers

\begin{tabular}{|c|c|c|c|}
\hline Phenotype & Stones & Interstitium & IMCD BD \\
\hline ICSF & $\mathrm{CaOx}$ & Heavy plaque & Nothing \\
\hline Obesity & $\mathrm{CaOx}$ & No plaque & Apatite plugs \\
\hline \multicolumn{4}{|l|}{ Bypass } \\
\hline \multirow[t]{2}{*}{$\mathrm{CaP} \mathrm{SF}$} & Brushite & Plaque & Apatite plugs \\
\hline & Apatite & Plaque & Apatite plugs \\
\hline dRTA & Apatite & Plaque & Apatite plugs \\
\hline Cystinuria & Cystine & Normal plaque & $\begin{array}{l}\text { Apatite and } \\
\text { cystine plugs }\end{array}$ \\
\hline $\begin{array}{l}\text { Primary } \\
\text { hyperparathyroid }\end{array}$ & $\begin{array}{l}\mathrm{CaOx} \\
\text { Apatite }\end{array}$ & Heavy plaque & Apatite plugs \\
\hline
\end{tabular}

Value for normal plaque $0.5 \%$; value for plaque $1 \%$; value for heavy plaque $7 \%$ [31]. IMCD inner medullary collecting duct, $B D$ Bellini duct, ICSF idiopathic calcium stone former, $C a P$ SF calcium phosphate stone former, $\mathrm{CaOx}$ calcium oxalate, $d R T A$ distal renal tubular acidosis 

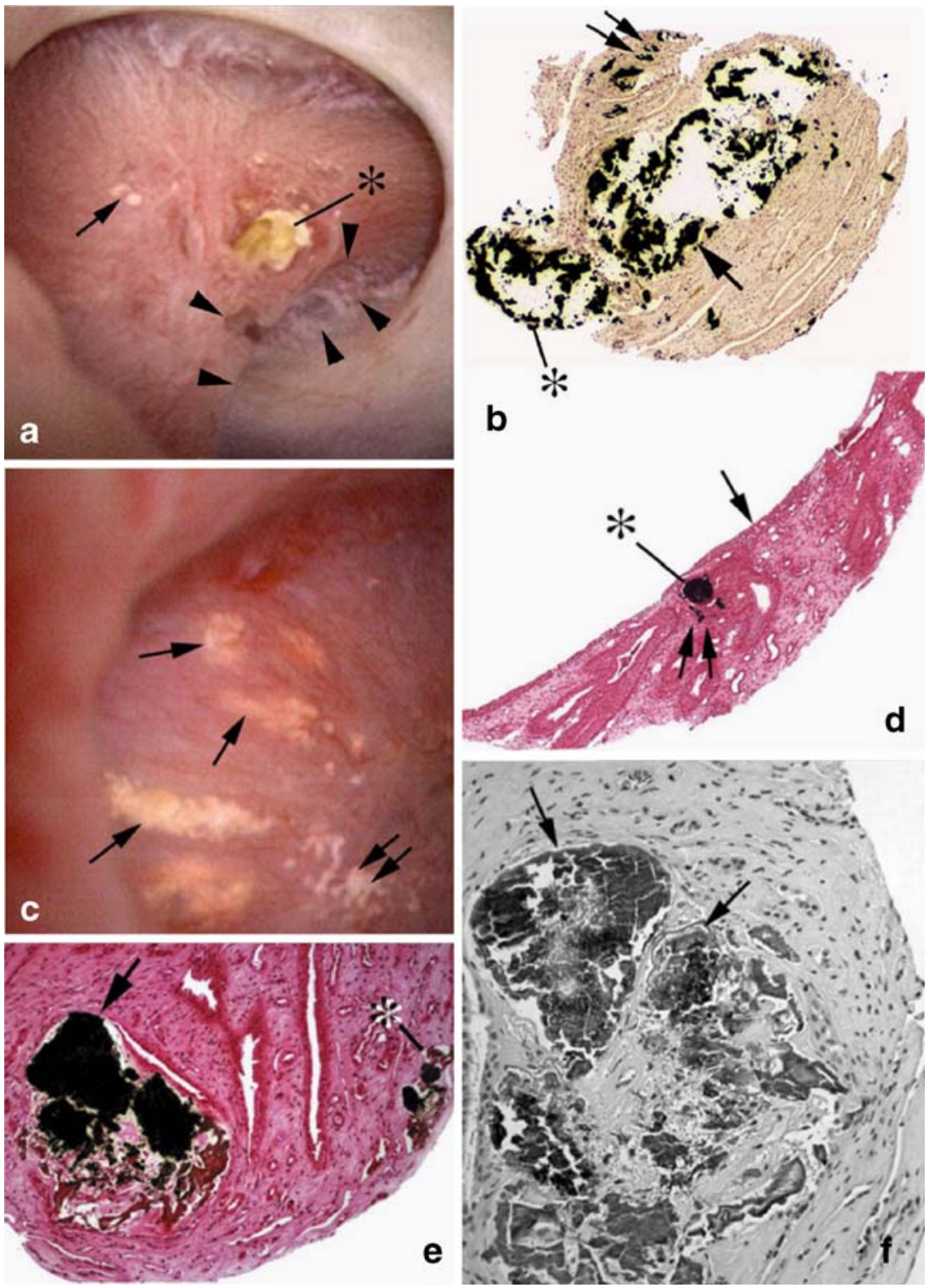

Fig. 7 Endoscopic and histologic images showing three distinct papillary patterns of crystal deposits in brushite patients. a Two of the three crystalline patterns are demonstrated: (1) small irregular white areas of suburothelial plaque (arrow), termed Randall's plaque, and (2) yellowish crystalline deposit at the opening of a duct of Bellini. Note a defect in the side of this papilla marked by arrowheads. b Biopsy through a brushite papilla revealing an enormously dilated inner medullary collecting duct/duct of Bellini (single arrow), with Yasuepositive mineral protruding from the opening of this duct (asterisk). Double arrow is a site of Randall's plaque. c Sites of Randall's plaque

(double arrow) (the first pattern) and the third crystalline pattern, which is a yellowish deposit in the inner medullary collecting ducts forming a spoke and wheel-like pattern (single arrows). These yellowish deposits are clearly seen in the collecting ducts (asterisk) in $\mathbf{d}$. The arrow points out the urothelium, while the double arrow is at the site of a Randall's plaque. The brushite papillae have large regions of disrupted to destroyed papillae that are filled with Yasue-positive mineral (e, arrow and asterisk). This same area is seen in $\mathbf{f}$, but it is now stained with hematoxylin and eosin (H\&E) to show the extensive interstitial fibrosis around these damaged papillary ducts (arrows)

extending from ducts of Bellini have never been found to be $\mathrm{CaOx}$ stones but, instead, have been apatite stones. In patients that have undergone intestinal bypass surgery for obesity and in cystinuric stone formers the stones appear to have formed in free solution. The only group that shows both attached $\mathrm{CaOx}$ stones and stones attached to plugs are those patients with primary hyperparathyroidism. Our recent studies using a combination of intra-

operative endoscopic mapping and papillary biopsies have clearly shown distinct patterns of histopathologic characteristics for each type of kidney stone former that predicts the mechanism of stone formation.

Acknowledgments This work was funded in part by grant no. NIH PO1 DK56788 and the Educational Initiatives of the International Kidney Stone Institute (IKSI). 
Fig. 8 Endoscopic and histologic images from a cystinuric stone former. Papillary morphology varies from normal (a and $\mathbf{b}$ ) to flattened and deformed (c and d). d A loop of Henle, filled with apatite deposits, and a grossly dilated inner medullary collecting duct (asterisk). Cystine plugs are seen protruding from the dilated mouths of ducts of Bellini (e). Medullary tubules of cystinuric patients may be filled with either cystine at the ducts of Bellini or apatite along inner medullary collecting ducts or loops of Henle (f)
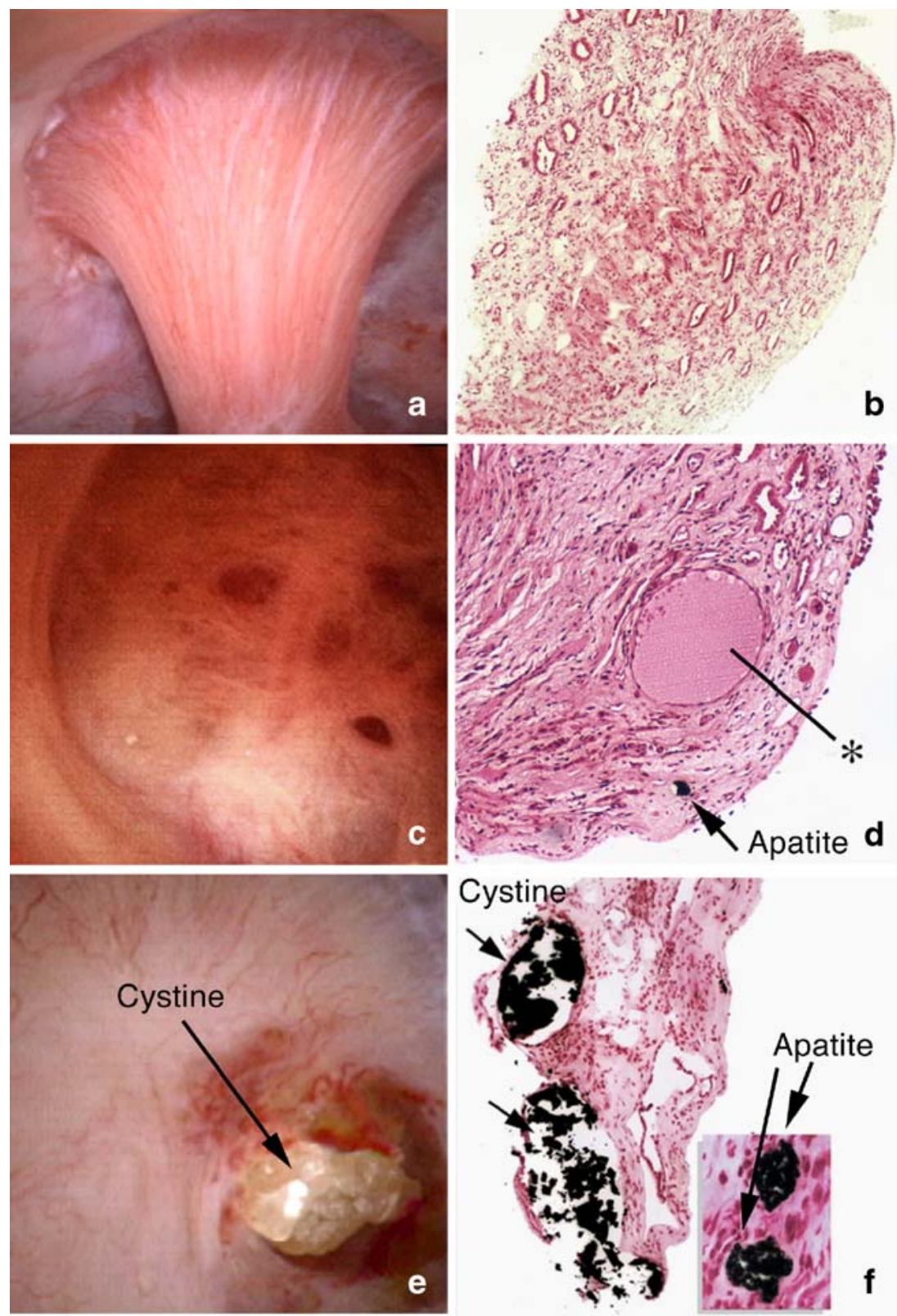

\section{Questions (answers appear following the reference list)}

1. Most kidney stones in the Western world are composed of:
a. uric acid (UA) and calcium phosphate $(\mathrm{CaP})$
b. uric acid and calcium oxalate $(\mathrm{CaOx})$
c. struvite and calcium phosphate
d. calcium oxalate $(\mathrm{CaOx})$ and calcium phosphate

2. Recent histopathologic data suggest that idiopathic calcium oxalate stone formers develop kidney stones:

a. attached to mineral plugs protruding from ducts of Bellini

b. in "free solution" in the renal collection system c. attached to the surface of a renal papilla at sites of interstitial plaque

d. due to crystal attachment to injured collecting duct cells

3. The interstitial plaque (termed Randall's plaque) found forming in the basement membrane of the thin loops of Henle is composed primarily of:
a. calcium oxalate
b. calcium phosphate
c. brushite
d. struvite

4. Potassium citrate salts may promote the formation of:

a. calcium oxalate stones 

b. calcium phosphate stones
c. uric acid stones
d. struvite stones

5. The type of kidney stone showing a worrisome increase in prevalence over the past two decades is:
a. calcium oxalate
b. calcium phosphate
c. uric acid
d. struvite

\section{References}

1. Pearle MS, Calhourn EA, Curhan GC (2005) Urologic diseases in America project: urolithiasis. J Urol 173:848-857

2. Stamatelou KK, Francis ME, Jones CA, Curhan GC (2003) Time trends in reported prevalence of kidney stones in the United Sates: 1976-1994. Kidney Int 63:1817-1923

3. Mandel NS, Mandel I, Fryjoff K, Rejniak T, Mandel G (2003) Conversion of calcium oxalate to calcium phosphate with recurrent stone episodes. J Urol 169:2026-2029

4. Parks JH, Worcester EM, Coe FL, Evan AP, Lingeman JE (2004) Clinical implications of abundant calcium phosphate in routinely analyzed kidney stones. Kidney Int 66:777-785

5. Parks JH, Coe FL, Evan AP, Worcester EM (2009) Urine pH in renal calcium stone formers who do and do not increase stone phosphate content with time. Nephrol Dial Transplant 24:130-136

6. Klee LW, Brito CG, Lingeman JE (1991) The clinical implications of brushite calculi. J Urol 145:715-718

7. Soucie JM, Coates R, McClellan W, Austin H, Thun M (1996) Relation between geographic variability in kidney stones prevalence and risk factors for stones. Am J Epidemiol 143:487-495

8. Brikowski TH, Lotan Y, Pearle MS (2008) Climate-related increase in the prevalence of urolithiasis in the United States. Proc Natl Acad Sci U S A 105:9841-9846

9. Lingeman JE, Matlaga B, Evan AP (2006) Surgical management of urinary lithiasis. In: Walsh PC, Retik AB, Vaughan ED, Wein AJ (eds) Campbell's urology, chap 44. Saunders, Philadelphia, pp 1431-1507

10. Coe FL, Evan AP, Worcester E (2005) Kidney stone disease. J Clin Invest 115:2598-2608

11. Verkoelen CF, Verhulst A (2007) Proposed mechanisms in renal tubular crystal retention. Kidney Int 72:13-18

12. Vermeulen CW, Lyon ES (1968) Mechanisms of genesis and growth of calculi. Am J Med 45:684-692

13. Finlayson B, Reid F (1978) The expectation of free and fixed particles in urinary stone disease. Invest Urol 15:442-448

14. Kok DJ, Khan SR (1994) Calcium oxalate nephrolithiasis, a free or fixed particle disease. Kidney Int 46:847-854

15. Escobar C, Byer KJ, Khan SR (2007) Naturally produced crystals obtained from kidney stones are less injurious to renal tubular epithelial cells than synthetic crystals. BJU Int 100:891-897

16. Randall A (1940) The etiology of primary renal calculus. Int Abstr Surg 71:209-240

17. Evan A, Lingeman JE, Coe FL, Shao Y, Parks H, Bledsoe SB, Sommer AJ, Paterson RJ, Kuo RL, Kim S, Grynpas M (2005) Crystal associated nephropathy in patients with brushite nephrolithiasis. Kidney Int 67:576-591

18. Evan AP, Lingeman J, Coe F, Shao Y, Miller N, Matlaga B, Phillips C, Sommer A, Worcester EM (2007) Renal histopathology of stone-forming patients with distal renal tubular acidosis. Kidney Int 71:795-801

19. Evan AP, Lingeman JE, Coe FL, Parks JH, Bledsoe SM, Shao Y, Sommer A, Paterson R, Kuo R, Grynpas M (2003) Randall plaque of patients with nephrolithiasis begins in basement membranes of thin loops of Henle. J Clin Invest 111:607-616

20. Evan AP, Coe FL, Lingeman JE, Shao Y, Matlaga BR, Kim SC, Bledsoe SB, Sommer AJ, Grynpas M, Philips CL, Worcester EM (2006) Renal crystal deposits and histopathology of the kidney in cystinuria. Kidney Int 69:2227-2235

21. Evan AP, Coe FL, Rittling SR, Bledsoe SB, Shao Y, Worcester EM, Lingeman JE (2005) Apatite plaque particles in inner medulla of kidneys of $\mathrm{CaOx}$ stone formers: osteopontin localization. Kidney Int 68:145-154

22. Evan AP, Bledsoe S, Worcester EM, Coe FL, Lingeman JE, Bergsland KJ (2007) Renal inter-alpha-trypsin inhibitor heavy chain 3 increase in calcium oxalate stone-forming patients. Kidney Int 72:1503-1511

23. Evan AP, Coe FL, Gillen D, Lingeman JE, Bledsoe S, Worcester EM (2008) Renal intraluminal crystals and hyaluronan staining occur in stone formers with bypass surgery but not with idiopathic calcium oxalate stones. Anat Rec 291:325-334

24. Matlaga BR, Williams JC, Kim SC, Kuo RL, Evan AP, Bledsoe SB, Coe FL, Munch LC, Lingeman JE (2006) Endoscopic evidence of calculus attachment to Randall's plaque. J Urol 175:1720-1724

25. Miller NL, Gillen DL, Williams JC, Evan AP, Bledsoe SB, Coe FL, Worcester EM, Matlaga BR, Munch LC, Lingeman JE (2008) A formal test of the hypothesis that idiopathic calcium oxalate stones grow on Randall's plaque. BJU Int doi:10.1111/j.1464410X.2008.08193.x

26. Cifuentes-Delatte L, Minon-Cifuentes J, Medina JA (1985) Papillary stones: calcified renal tubules in Randall's plaques. J Urol 133:490-494

27. Pieras E, Costa-Bauza A, Ramis M, Grases F (2006) Papillary and nonpapillary calcium oxalate monohydrate renal calculi: comparative study of etiologic factors. TSW Urol 1:116-124

28. Daudon M, Traxer O, Jungers P, Bazin D (2007) Stone morphology suggestive of Randall's plaque. In: Evan AP, Lingeman JE, Williams JC (eds) Renal stone disease: proceedings of the First International Urolithiasis Research Symposium. American Institute of Physics, Melville, NY, pp 26-34

29. Evan AP, Coe FL, Lingeman JE, Shao Y, Sommer AJ, Bledsoe SB, Anderson JC, Worcester EM (2007) Mechanism of formation of human calcium oxalate renal stones on Randall's plaque. Anat Rec 290:1315-1323

30. Evan AP, Lingeman JE, Coe FL, Miller N, Bledsoe S, Sommer A, Williams J, Shao Y, Worcester E (2008) Histopathology and surgical anatomy of patients with primary hyperparathyroidism and calcium phosphate stones. Kidney Int 74:223-229

31. Vermooten V (1942) The origin and development in the renal papilla of Randall's calcium plaque. J Urol 48:27-37

32. Kuo RL, Lingeman JE, Evan AP, Paterson RF, Parks JH, Bledsoe SB, Munch LC, Coe FL (2003) Urine calcium and volume predict coverage of renal papilla by Randall's plaque. Kidney Int 64:2150 2154

33. Kim SC, Coe FL, Tinmouth WW, Kuo RL, Paterson RF, Parks JH, Munch LC, Evan AP, Lingeman JE (2005) Stone formation is proportional to papillary surface coverage by Randall's plaque. J Urol 173:117-119

\section{Answers:}

1. d. calcium oxalate $(\mathrm{CaOx})$ and calcium phosphate

2. c. attached to the surface of a renal papilla at sites of interstitial plaque

3. b. calcium phosphate

4. b. calcium phosphate stones

5. b. calcium phosphate 